\title{
Performance tests of two insertion type thermal mass flow meters
}

\author{
I CARE $^{1}, \mathrm{~J} \mathrm{VEAU}^{2}$, Ph GENOUX ${ }^{3}$ \\ ${ }^{1}$ CETIAT, Domaine scientifique de la Doua, 25 avenue des Arts, 69100 Villeurbanne, France \\ ${ }^{2} E D F R \& D$, Département STEP, 6 quai Watier, BP 49, 78401 Chatou, France \\ ${ }^{3}$ EXERA, 4 Cité d'Hauteville, 75010 Paris, France \\ E-mail : isabelle.care@cetiat.fr
}

\begin{abstract}
Thermal mass flow meters are widely used in industry for process and plant mass flow metering for a wide range of gas types. The interest of this type of flow meter lies in the fact that the induced pressure drop is negligible; the wide turndown allows measurement of gas consumption as well as leaks. However, the operating conditions of flow meters are sometimes far from the conditions for which the manufacturer specifications are given and the objective of the performed tests is therefore the evaluation of the measurement error which can occur when the use conditions deviate from the calibration conditions. First, tests in "ideal" conditions (no upstream disturbances, ambient conditions of pressure, temperature and humidity) have been performed to check if the flow meters meet their manufacturer's specifications. Then, some operating conditions have been changed. The investigated parameters were the gas temperature, the gas humidity, the in-line pressure, the orientation of the sensor relative to the flow direction and the distance to upstream disturbances. Tests have been conducted with upstream distances equal to, smaller and higher than the minimum distance required by the manufacturer. The study presented in this paper has been conducted for two insertion type thermal mass flow meters.
\end{abstract}

\section{Introduction}

The working principle of an insertion type thermal mass flow meter is based on the measurement of the cooling effect of a flowing gas on a heated probe.

Insertion type devices have two probes that are inserted in the flowing gas as shown in Figure 1. Each probe is a resistive temperature sensor.

C The Authors, published by EDP Sciences. This is an open access article distributed under the terms of the Creative Commons Attribution 


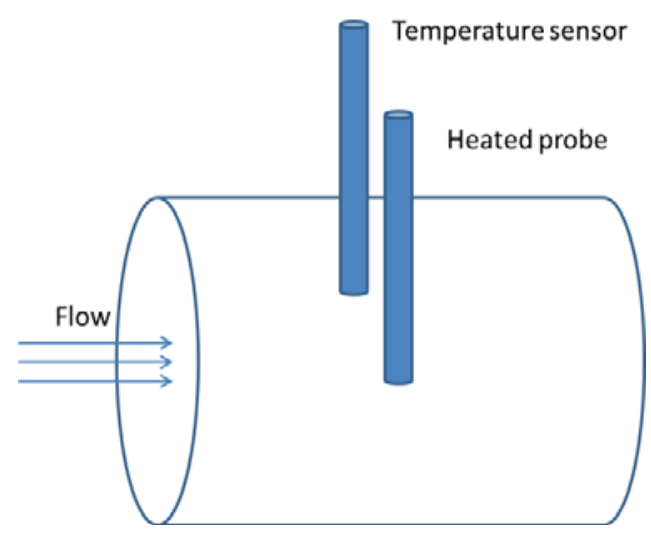

Figure 1 - Insertion thermal mass flow meter

One monitors the gas temperature while the other is heated. The heat flux between this probe and the gas, $\mathrm{H}$, is proportional to the mass flow rate, $\mathrm{qm}$, and the temperature difference, $\Delta \mathrm{T}$ :

$$
q m=K \times\left(\frac{H}{\Delta T}\right)^{n}
$$

The measurement of the electrical power brought to heat the probe is directly related to the heat exchange flux with the flowing gas and then with the mass flow rate.

The insertion type thermal mass flow meter allows measurements of gas flow rates in, even large, circular pipes and rectangular ducts with a cost-effective and easy installation. With a large turndown, it can also measure operational flow rates as well as leakage.

However, as the heat exchange flux depends also to some secondary parameters such as viscosity, thermal conductivity of the fluid, the behavior of the meter can be influenced by the nature of the flowing fluid.

The technical commission "Flow-metering, Level-metering" of EXERA1, , have defined a test program aiming at evaluating the performances of insertion type thermal mass flow meters not only in laboratory conditions used in the manufacturers' specifications sheets, but also in some conditions representative of on-site environment.

1 EXERA is a French association gathering companies that operate measuring instruments, automatisms and actuators, and are willing to exchange information on their measurement experiences. For more information, please visit www.exera.com 


\section{Evaluated Flow meters and test program}

The insertion type thermal mass flow meters were lent by the manufacturers who approved the proposed test program.

Table 1 - Evaluated flow meters

\begin{tabular}{|c|c|c|}
\hline Manufacturer & \multicolumn{2}{|c|}{ Model } \\
\hline E+H & PROLINE T-MASS 65I \\
\hline FCI & ST 100 \\
\hline
\end{tabular}

Tests were performed in the CETIAT's (France) COFRAC accredited gas flow laboratory. The reference flow rate was measured using a set of critical nozzles with a measuring uncertainty of $0.31 \%$ of the flow rate and the tests were conducted with air as gas fluid.

First the measured performances of the flowmeters were compared to the manufacturer's specifications at atmospheric pressure, ambient temperature and under ideal conditions. These one were defined in terms of minimum upstream and downstream straight lengths. A DN 100 pipe was used for these tests

Then, some test conditions were changed to evaluate their influence on the measurement of the flow meters. These conditions were :

- Temperature,

- Relative humidity,

- Pressure,

- Distance from upstream disturbances.

All these tests were performed with the flow meter inserted in a DN100 pipe. An additional test was performed in a DN300 pipe with appropriate upward and downward straight lengths.

Results are presented here anonymously for reason of confidentiality. The detailed results are exclusively available to EXERA members in reports [1] and [2]. 


\section{Results}

\subsection{Metrological performances}

The metrological performances were evaluated with air at atmospheric pressure and at the following conditions:

- Pipe diameter: DN 100

- Flow rates: 5 between 0.01 Qmax and Qmax

- Upstream/downstream straight lengths: 40D/10D

- Ambient air

Results are presented below are typical ones obtained for one or the other of the two flow meters:

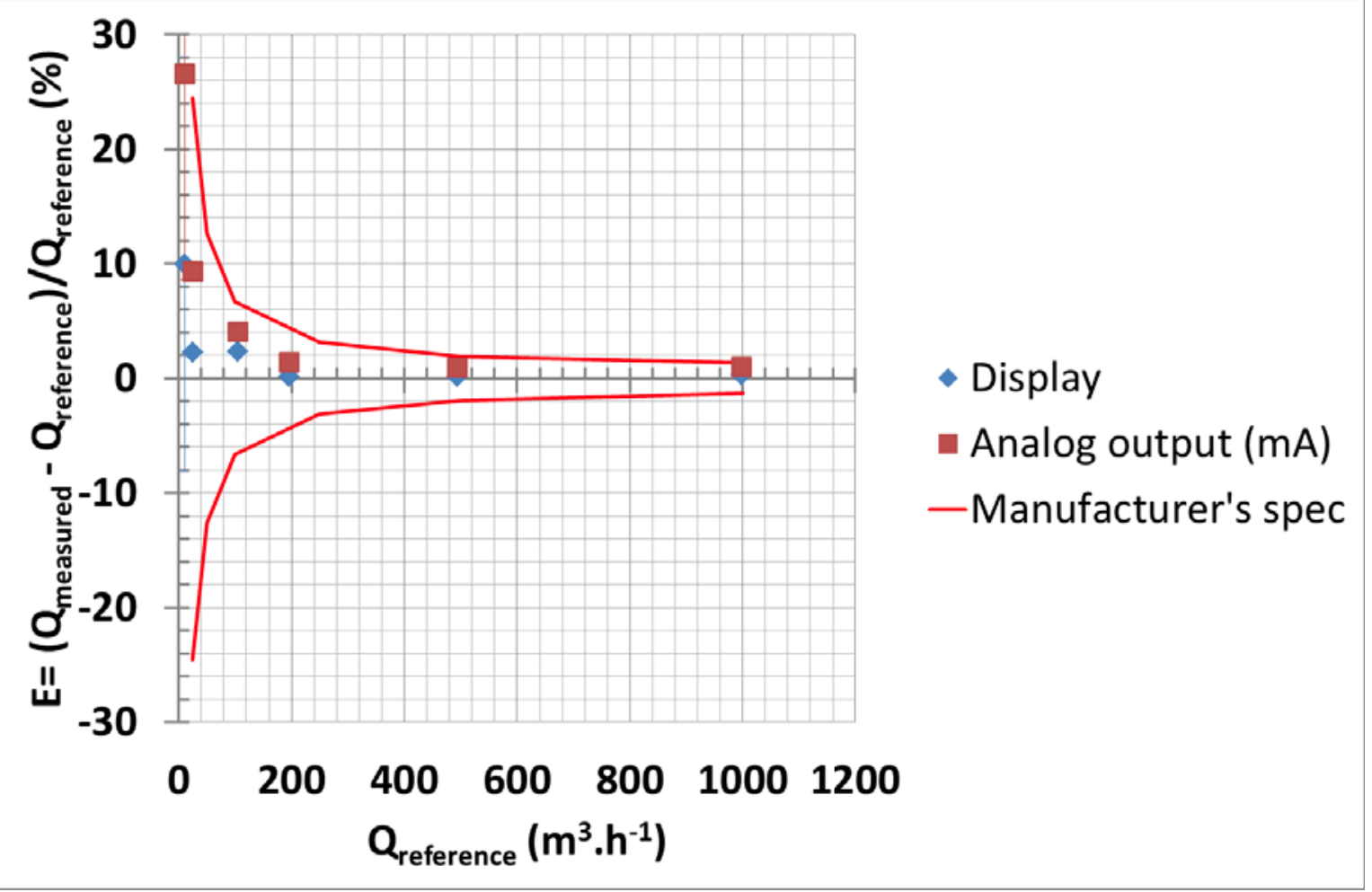

Figure 2 - Metrological performances of one of the two tested flow meters

The flow meter is in compliance with the manufacturer's specifications both for analog output and for reading on the display over the whole flow range.

\subsection{Influence of pressure, temperature and humidity conditions}

As the measurement is directly related to the heat exchange flux between the flow sensor and the flowing gas, some changes in the gas properties could have an influence of the results. these parameters have been tested by comparing results:

- with dry and humidified compressed air at 1 bar abs,

- $\quad$ with air at 10,22 and $40^{\circ} \mathrm{C}$, 
- $\quad$ with compressed air at 1 bar and 6 bar abs.

The results of the tests are shown below:

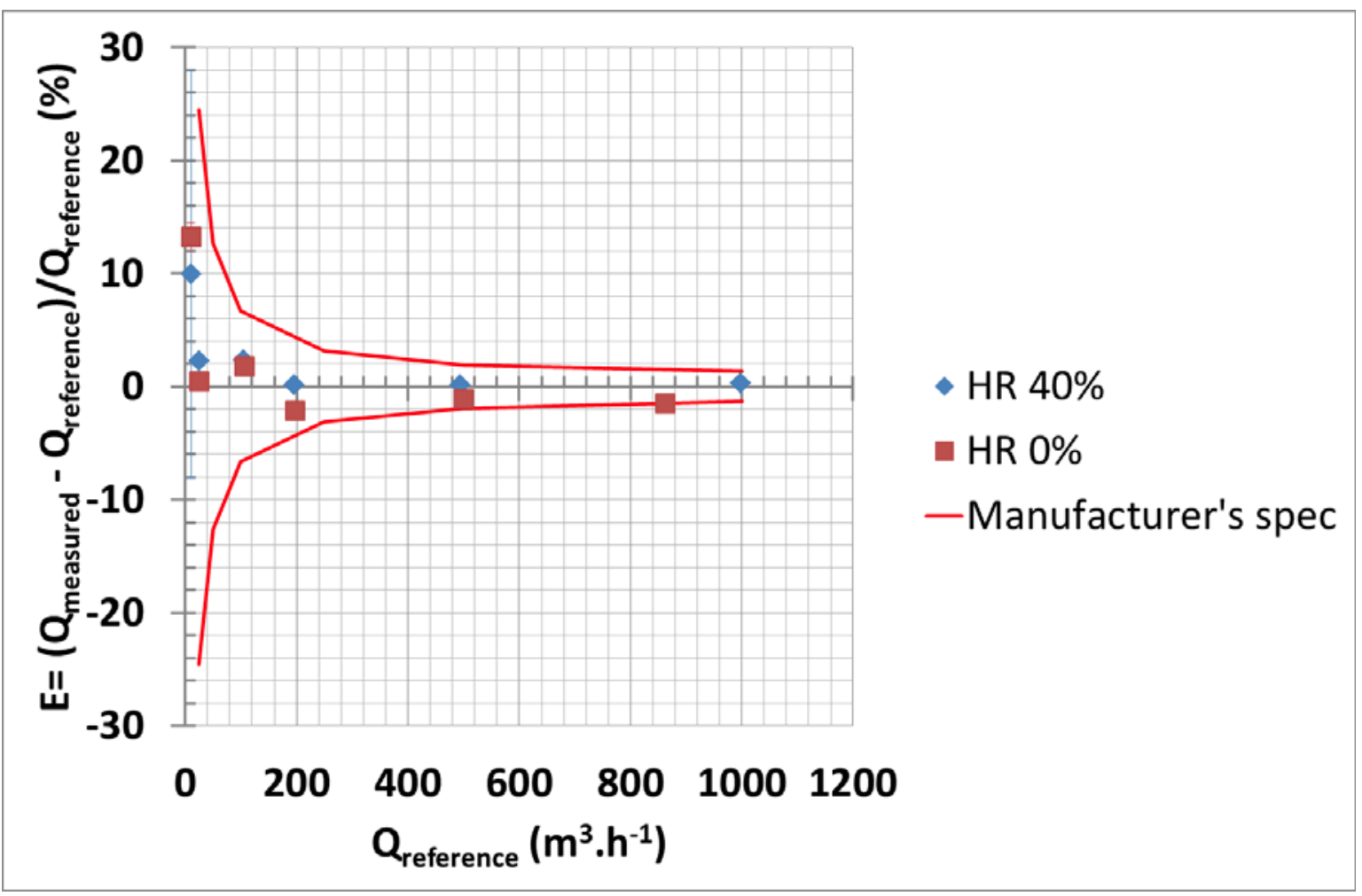

Figure 3 - Influence of relative humidity of the air on one of the two tested flow meters

It can be observed that the relative humidity of the air has no significant influence on the flow rate measured by the flow meter under test. 


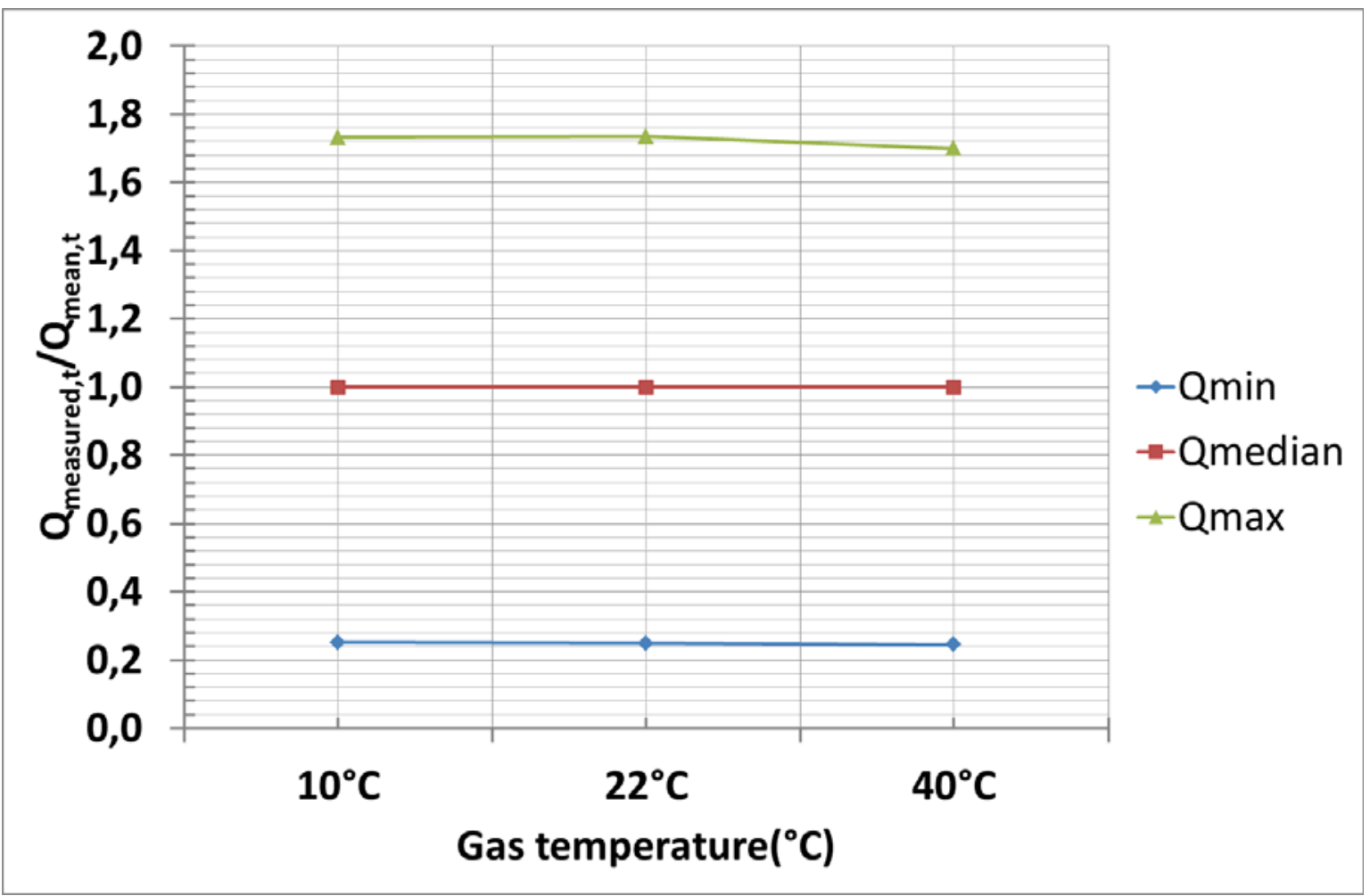

Figure 4 - Influence of gas temperature on one of the two tested flow meters

On the figure above, the ratio between the flow rate measured when the temperature of air is $t$ divided by the median flow rate at the same temperature $t$ is drawn against the temperature $t$. The tests have been performed at $10^{\circ} \mathrm{C}, 22^{\circ} \mathrm{C}$ and $40^{\circ} \mathrm{C}$ for three flow rates, Qmin, Qmedian and Qmax. Even if the temperature change has an impact of the fluid properties, it can be seen that the influence on the flow rate measured by the flow meter under test is not significant. 


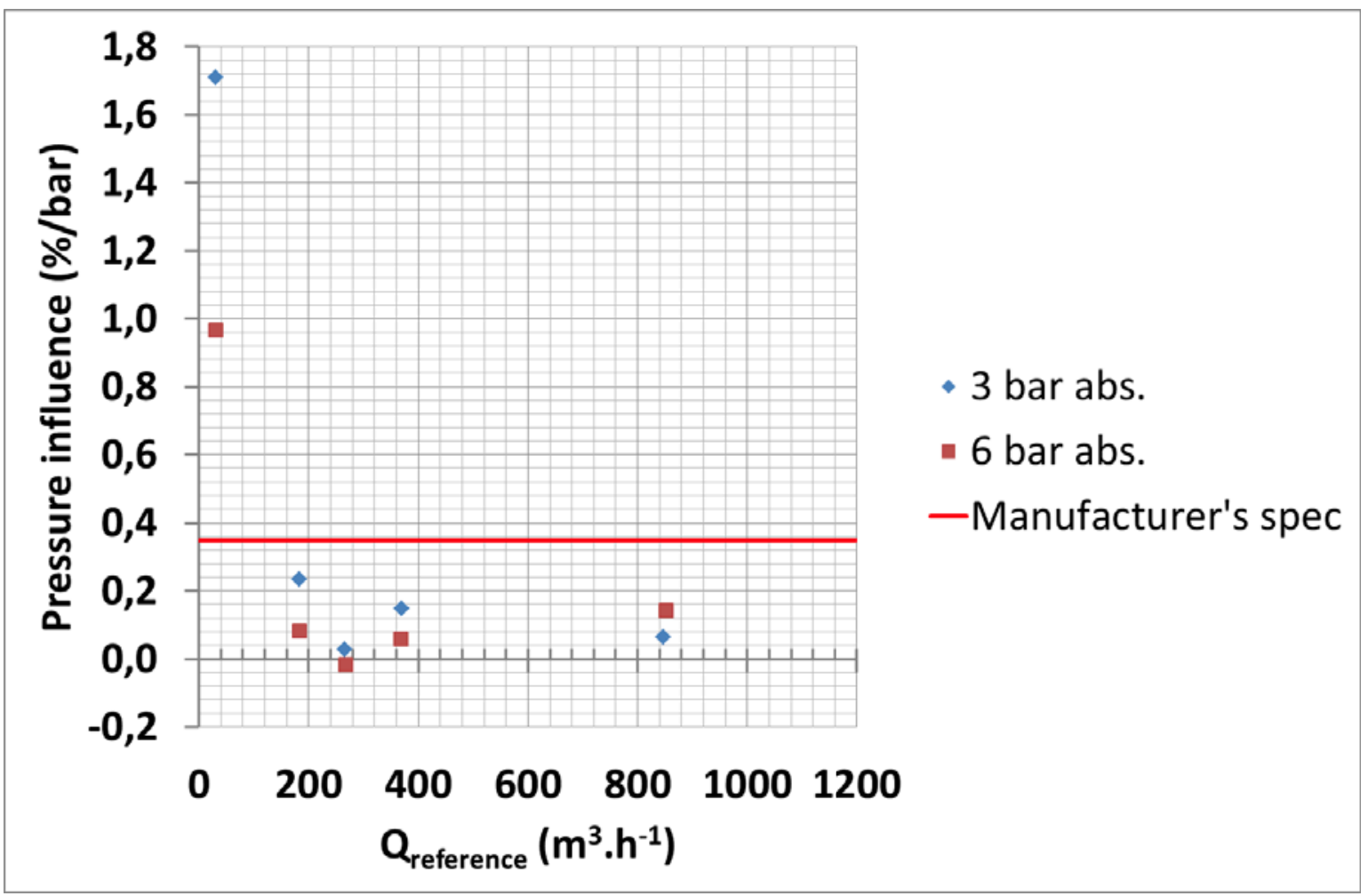

Figure 5 - Influence of pressure on one of the two tested flow meters

An dependence of the measurement to in-line pressure is sometimes given in the specification's sheet of the flow meter. This one is often expressed as an additional error in $\%$ of deviation/bar. The tests have been performed at 1,3 and 6 bar abs and the results presented on the figure above show a slight dependence for the flow meter under test, in agreement with the manufacturer's specification except at the very low flow rate.

\subsection{Influence of shortened upstream straight lengths}

In real conditions, it is sometimes difficult to reach the minimum straight lengths specified by the manufacturers. It is then interested to have an idea of the behavior of the flow meters in such conditions.

If the velocity profile is distorted because of upstream disturbances, the error on the mean velocity might occur because the working principle of the flow rate measurement of this type of flow meter is based on the assumption of a well-established turbulent flow in the duct. To estimate the influence of shortened straight lengths, tests were performed with some disturbances at different distances upstream the flow meter. The disturbances which have been used are a single bend and a double non coplanar bend at different distances, according Table 2, below. 
Table 2 - Experimental conditions

\begin{tabular}{|c|c|c|}
\hline Disturbance type & Upstream straight length & Downstream straight length \\
\hline & $\mathrm{XD}-5 \mathrm{D}$ & $10 \mathrm{D}$ \\
Single bend at $90^{\circ}$ & $\mathrm{XD}$ & $10 \mathrm{D}$ \\
& $\mathrm{XD}+5 \mathrm{D}$ & $10 \mathrm{D}$ \\
\hline \multirow{2}{*}{ Non coplanar double bend at } & $\mathrm{XD}-5 \mathrm{D}$ & $10 \mathrm{D}$ \\
$90^{\circ}$ & $\mathrm{XD}$ & $10 \mathrm{D}$ \\
& $\mathrm{XD}+5 \mathrm{D}$ & $10 \mathrm{D}$ \\
\hline
\end{tabular}

The minimum upstream straight length is defined as $\mathrm{XD}$, where $\mathrm{X}$ depends on the manufacturer and may also depend on the type of disturbance.

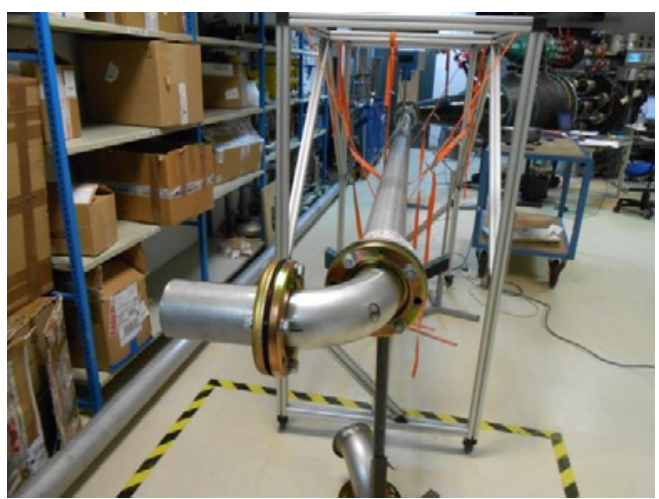

Single bend

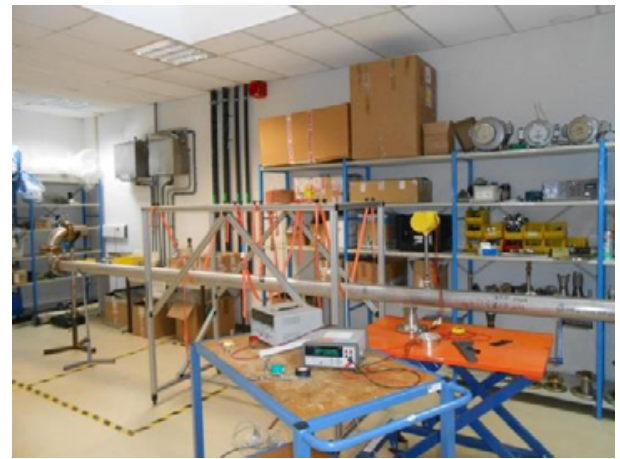

Non coplanar double bend

Figure 6 - Photos of the disturbances

The results are presented below first for a single bend and then for a double non coplanar bend. 


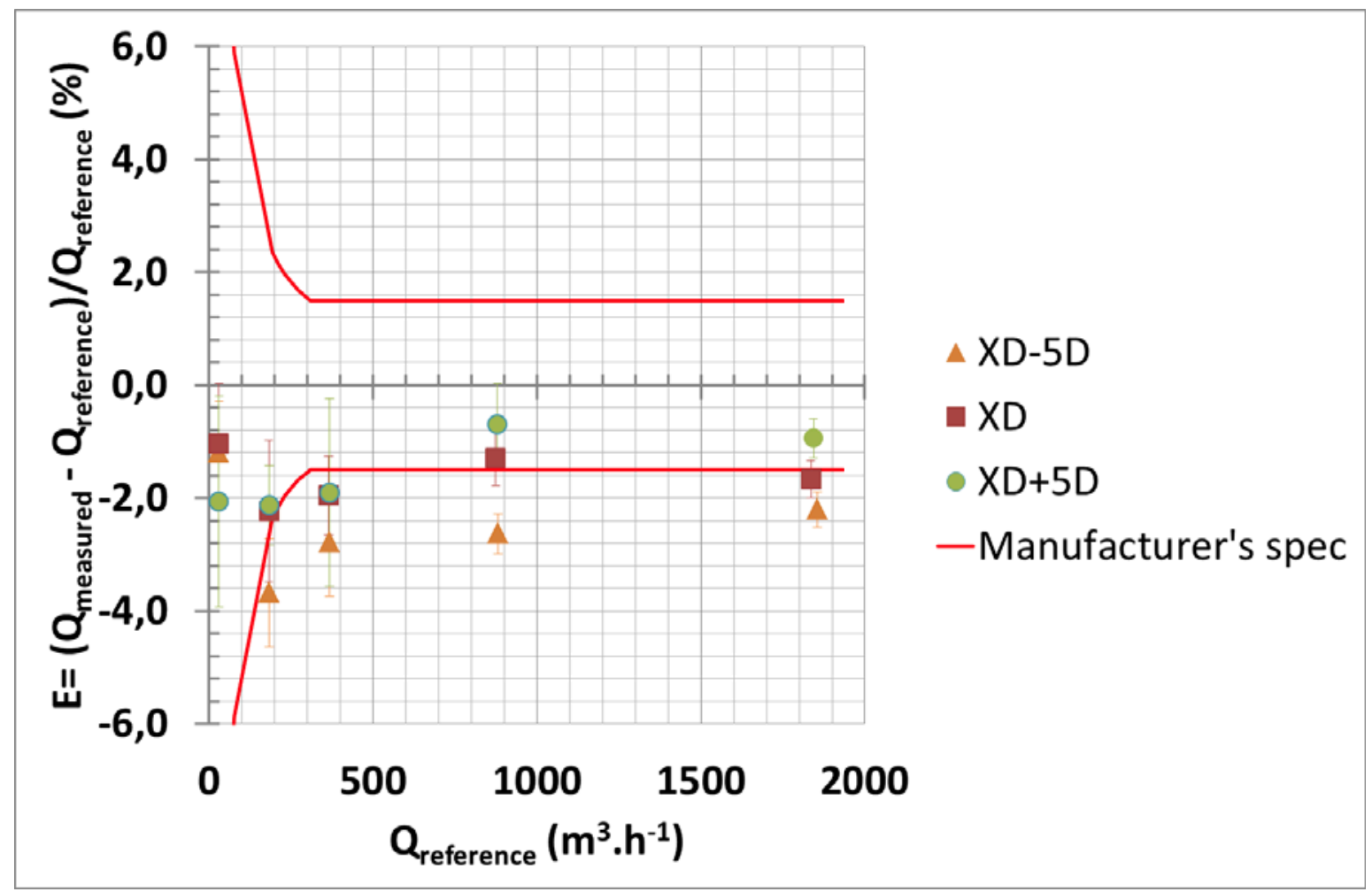

Figure 7 - Influence of an upstream single bend at $90^{\circ}$

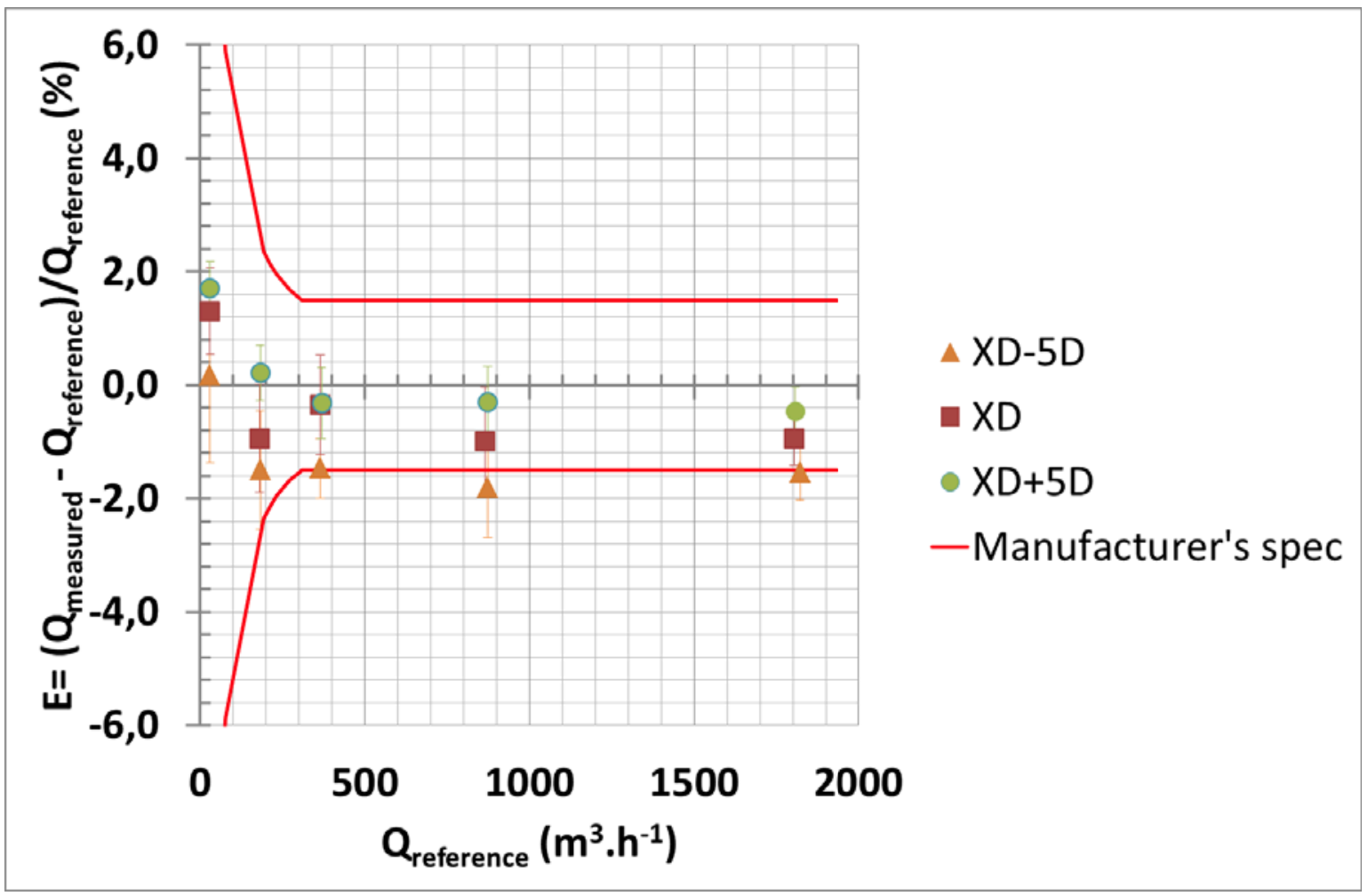

Figure 8 - Influence of an upstream non coplanar double bend

The results presented above show the significant influence of the straight length on the measured flow rate. 


\section{Conclusions}

Two insertion type thermal mass flow meters, available on the market, were evaluated in different conditions. A comparison with manufacturers' specifications was performed with air as flowing fluid. Each of the two flow meters' response is mainly within the manufacturers' specifications.

The flow meters were then evaluated in some extreme conditions representative of on-site conditions. The tested conditions were shortened upstream straight lengths, as well as change in temperature, pressure and relative humidity. A small dependence on the inline pressure is observed, demonstrating the primary mesurand of the thermal mass flowmeter is not a "real" mass flow. The dependence on upstream straight lengths shows how important it is to respect the manufacturer's recommendations.

\section{Thanks}

We would like to thank EXERA that funded the evaluation campaign, and its technical commission "Flow-metering, Level-metering" who defined the test protocol, and the manufacturers (Endress+Hauser and FCI through its French representative Engineering Mesures) for their financial and technical contributions.

\section{References}

[1] CARÉ I., Évaluation d'un débitmètre massique thermique à insertion Proline t-mass 65I Endress+Hauser, Rapport EXERA E6070X17, 2017

[2] CARÉ I., Évaluation d'un débitmètre massique thermique à insertion ST100 FCI, Rapport EXERA E6071X17, 2017 